\title{
Benzodiazepine Dependence Studies in Animals: An Overview
}

\author{
James H. Woods \\ Departments of Pharmacology and Psychology, University of Michigan, Ann \\ Arbor, Michigan
}

\begin{abstract}
Woods, J.H.: Benzodiazepine dependence studies in animals: an overview. Drug Dev. Res. S1:077-081, 1982.

A selective review of benzodiazepine dependence studies in animals is presented, emphasizing areas of drug self-injection, drug discrimination, and physiological dependence. Benzodiazepines as a class, as well as long-acting barbiturates, appear to maintain drug self-injection behavior less well than ultrashort-acting barbiturates. The duration of action as well as the rapidity of onset of these drugs may be important determinants of their reinforcing efficacy. Drug discrimination procedures may allow evaluation of the relative rapidity at onset and duration of action of these drugs to evaluate this and related hypotheses.
\end{abstract}

Key words: benzodlazepines, primates, relnforcement, drug self-Injectlon, drug discrimination, dependence

\section{INTRODUCTION}

A discussion of the abuse potential of a drug or drug class must first establish its rules of evidence for such potential. One important methodological guide for gaining evidence of abuse potential is that of pharmacological equivalence [Martin, 1977]. If the drug in question is shown to be pharmacologically equivalent to a standard drug that has demonstrated abuse potential, the comparison drug can also be assumed to have abuse potential. The determination of pharmacological equivalence involves comparisons of a series of dose-effect relations involving measures of potency and efficacy against a standard or standards of reference. One appropriate test in this situation is to evaluate the ability of both the standard and test compounds to maintain self-administration behavior. Another test of pharmacological equivalence that may be relevant to abuse potential is evaluation of the similarity of the discriminative stimulus properties of a standard and a comparison drug. Tests of equivalence of physiological dependence have been used to evaluate the abuse potential of narcotics, a procedure that is likely to be relevant to sedatives and anxiolytics as well.

Address reprint requests to Dr. James H. Woods, PhD, Department of Pharmacology, University of Michigan Medical School, Ann Arbor, MI, 48109. 
A drug's abuse potential, once determined, must be weighed against its therapeutic potential, again using a series of dose-effect relations. As Thompson [1977] pointed out, an ideal drug would produce therapeutic effects at doses below those necessary to maintain drug self-administration. To be specific to this presentation, one would want measures of potency and efficacy of the various benzodiazepines in tasks predictive of their therapeutic use, namely, the treatment of situational anxiety, insomnia, and convulsive disorders, including the alcohol-withdrawal syndrome. This information could then be compared to the data on abuse potential. Ideally, all of these data would be obtained using tests, species, and routes of administration that have been shown to be predictive in human studies.

This paper is directed toward a discussion of issues concerning the abuse potential of anxiolytics as measured by evaluation of their discriminative stimulus properties, reinforcing properties, and potential for producing physiological dependence.

\section{Stimulus Functions of Barbiturates and Benzodiazepines}

Drugs that have demonstrated abuse potential in man have, in a vast majority of the cases tested, also been shown to be both reinforcing stimuli and discriminative stimuli in nonhuman primates. A reinforcing stimulus is one that has the capacity to increase and maintain behavior that results in delivery of the stimulus. A discriminative stimulus is one in whose presence a particular behavior has been reinforced; the behavior is therefore likely to reoccur in the presence of that stimulus. Studies of the reinforcing and discriminative functions of benzodiazepines, especially in comparison to barbiturates, has provided some provocative information concerning the abuse potential of this class of drugs.

\section{Drug Self-Injection in Primates}

In studies of drug self-injection of the benzodiazepines in nonhuman primates, there have been two procedures used. In one type of study, often referred to as a continuous-access selfinjection study, the primate is given opportunity, without restriction, to self-inject dose units of the drug. The results allow the determination of pattern and amount taken over time, and perhaps as importantly, observation may be made of the form and severity of intoxication that is selfinduced under these conditions. It has been shown that severe intoxication may be demonstrated with this procedure with barbiturates, narcotics, and central nervous system stimulants [Deneau et al., 1969]. Yanagita and Takahashi [1970] reported that intravenous availability of $3 \mathrm{mg} / \mathrm{kg} / \mathrm{inj}$. pentobarbital resulted in the initiation and maintenance of self-injection responding in five of five monkeys. The amounts of drug delivered per day rose over the course of weeks and the monkeys spent considerable periods of time comatose - several multiples of the anesthetizing dose often being administered in a single day. A severe withdrawal syndrome was observed upon abrupt termination of the opportunity for self-injection. In comparison, availability of intragastric pentobarbital at $10 \mathrm{mg} / \mathrm{kg} / \mathrm{inj}$. was sufficient to initiate five of seven monkeys with an average barbiturate intake of approximately $120 \mathrm{mg} / \mathrm{kg} / \mathrm{day}$ at the end of 4 weeks of exposure; intake continued to climb until some of the monkeys were injecting over $400 \mathrm{mg} / \mathrm{kg} /$ day after 10 or more weeks. In contrast, phenobarbital, at a dose of $7.5 \mathrm{mg} / \mathrm{kg} / \mathrm{inj}$. i.v., did not yield enough self-injection to produce signs of intoxication [Deneau, as reported in Fraser and Jasinski, 1977]. With intravenous diazepam, using $0.4 \mathrm{mg} / \mathrm{kg} / \mathrm{inj}$., Yanagita and Takahashi [1973] reported an intake of 8 to $10 \mathrm{mg} /$ $\mathrm{kg} /$ day in rhesus monkeys. Severe signs of intoxication were absent throughout the chronic selfadministration period, although the monkeys were drowsy, ataxic, and less active. With chlordiazepoxide at $1 \mathrm{mg} / \mathrm{kg} / \mathrm{inj}$., three of four monkeys took up to a maximum of 31 injections but within 4 weeks were taking only a few injections each day. In two studies, monkeys with histories of i.v. stimulant self-injection were allowed access to intragastric chlordiazepoxide $(10 \mathrm{mg} / \mathrm{kg} / \mathrm{inj}$.) or oxazepam (10 mg/kg/inj.); neither drug condition produced significant amounts of drug intake or intoxication. With these data, it is apparent that pentobarbital maintains significantly more behavior and self-intoxication than these benzodiazepines. However, only limited conditions (e.g., a single dose) have been studied with small numbers of monkeys. In addition, it is difficult to grasp the type and degree of drug effect obtained from the observational data presented. 
In the second type of drug self-injection procedure used to evaluate benzodiazepines, monkeys are trained to self-inject a drug during a limited period of time each day. Various doses of other drugs are periodically substituted for the standard drug and are thereby assessed for their capacity to maintain drug-reinforced responding (substitution procedure). The rate of responding maintained by each drug under optimal dose conditions is taken as an indication of the reinforcing strength of the drug. Using this procedure, Hoffmeister [1977] found with i.v. drug delivery in rhesus monkeys that diazepam is more potent than pentobarbital; each drug maintained rates above saline at certain doses, but all doses maintained rates below those of codeine, the standard drug with which responding was initiated and maintained. Hackett and Hall [1977] failed to obtain rates of responding with diazepam $(0.05$ to $0.4 \mathrm{mg} / \mathrm{kg} / \mathrm{inj}$.) above vehicle controls in rhesus monkeys trained to inject codeine. As others [Griffiths and Ator, 1981] have noted, procedural details may be of considerable importance in producing these differences in diazepam self-injection. It should not be overlooked, nevertheless, that neither pentobarbital nor diazepam maintained self-injection responding as effectively as codeine in either study. More recently, Winger [personal communication] has studied self-injection of a series of barbiturates and benzodiazepines in rhesus monkeys maintained on a fixed-ratio 30, timeout 10 minute schedule of i.v. methohexital delivery. Under these conditions, $1.0 \mathrm{mg} / \mathrm{kg} / \mathrm{inj}$. methohexital maintained rates of responding of over 1 response/ $\mathrm{sec}$. Both lower and higher doses maintained lower rates of responding. Midazolam, a water soluble, short-acting benzodiazepine [Brown et al., 1979] maintained intermediate (30\% of methohexital) rates though definitely above rates maintained by saline administration. The optimal rate-maintaining dose was $0.10 \mathrm{mg} / \mathrm{kg} / \mathrm{inj}$. Neither diazepam $(0.032$ to $1.0 \mathrm{mg} / \mathrm{kg} / \mathrm{inj}$.) nor phenobarbital $(0.1$ to 10 $\mathrm{mg} / \mathrm{kg} / \mathrm{inj}$.) was distinguishable from vehicle as far as rates of self-administration were concerned.

Pentobarbital maintained rates slightly above those produced by saline at $1.0 \mathrm{mg} / \mathrm{kg} / \mathrm{inj}$. Here, it is important to note that the schedule of drug delivery allows opportunity for injection every $10 \mathrm{~min}$, thus favoring, in terms of rate maintenance, those compounds that have rapid onsets and brief durations of action. Nevertheless, a difference in rates of drug self-injection persists between the benzodiazepines and barbiturates with this procedure when comparing midazolam and methohexital, two compounds with rapid onsets and brief durations of action.

Using a similar procedure with baboons that were allowed $3 \mathrm{hr}$ between opportunities to inject a drug solution, Griffiths and colleagues [personal communication] studied a variety of barbiturates and benzodiazepines. The baboons were originally trained to self-inject cocaine. Upon substitution, amobarbital, secobarbital, and pentobarbital were found to be similar in potency and efficacy in maintaining self-injection performance, with virtually all available injections being taken at high rates at the optimal doses $(3.0$ to $10.0 \mathrm{mg} / \mathrm{kg}$ ). None of the benzodiazepines - clonazepam $(0.01$ to $10 \mathrm{mg} / \mathrm{kg}$ ), clorazepate $(0.01$ to $3.2 \mathrm{mg} / \mathrm{kg})$, diazepam $(0.3$ to $10 \mathrm{mg} / \mathrm{kg})$, flurazepam $(0.1$ to $32 \mathrm{mg} / \mathrm{kg})$, medazepam $(0.01$ to $10 \mathrm{mg} / \mathrm{kg})$, and midazolam $(0.03$ to $10 \mathrm{mg} / \mathrm{kg})$-maintained rates of self-injection comparable to the barbiturates. Two benzodiazepines (clonazepam and fiurazepam) appeared to maintain self-injection performance slightly above vehicle, while midazolam maintained higher rates, clearly intermediate between the rates maintained by the barbiturates and vehicle. Thus, a fair correspondence between these studies in the rhesus monkey and the baboon exist with the generalization of the limited reinforcing effects of benzodiazepines continuing to be a consistent finding.

\section{Drug Discrimination Studies in Primates}

In a variety of animals, including rats [Colpaert et al., 1976], pigeons [Herling et al., 1980], and rhesus monkeys [Winger and Herling, in press] the discriminative characteristics of barbiturates and benzodiazepines are somewhat similar. For example, Colpaert and his colleagues examined the ability of a variety of compounds to substitute for oral chlordiazepoxide $(5 \mathrm{mg} / \mathrm{kg})$ when this drug was used as a discriminative stimulus in rats. Bromazepam, diazepam, flurazepam, lorazepam, nitrazepam, oxazepam, as well as pentobarbital, phenobarbital, and glutethimide produced drugappropriate responding, while thalidomide, baclofen, chlorpromazine, and haloperidol did not. In the monkey, diazepam, methohexital, clobazam, phenobarbital, and barbital produce full drugappropriate responding in monkeys trained to discriminate s.c. injections of pentobarbital from 
saline, whereas ethylketazocine and dextromethorphan produce very little drug-appropriate responding, and codeine, dextrorphan, ketamine, and cyclazocine produce intermediate amounts [Winger and Herling, in press]. These studies of drug discrimination, although using different routes of administration from the drug-injection studies, suggest that the interoceptive effects of barbiturates and benzodiazepines are similar. We shall return to this point in the discussion of the human self-administration of benzodiazepines.

Using drug discrimination procedures it is possible to measure the time of onset and the duration of action of drugs that generalize to the training drug. So far, the data on the temporal course of the discriminative effect of barbiturates is related to their ability to maintain self-injection responding, in that methohexital has the most rapid onset and the shortest duration; with pentobarbital, onset is delayed and duration of action lengthened [Winger and Herling, in press]. Thus, barbiturates with rapid onsets and short durations of discriminative effects may have stronger reinforcing effects than their slower-acting relatives. Benzodiazepines are currently being evaluated in this procedure. The s.c. routes of benzodiazepine delivery give unreliable behavioral effects in keeping with their poor, rather erratic absorption from these sites. Oral administration produces less variable data, and indicates relative rapidity of onset of effects in the following order: pentobarbital $>$ phenobarbital $=$ diazepam $=$ clobazam.

\section{Drug Self-Administration Studies in Man}

There have been few quantitative controlled studies of barbiturate or benzodiazepine selfadministration in humans. Griffiths et al. $[1976,1979]$ demonstrated that subjects with a history of sedative abuse, housed in a residential ward, would self-administer both diazepam and pentobarbital via the oral route, whereas they would not self-administer placebo or active doses of chlorpromazine. Pentobarbital $(90 \mathrm{mg})$ maintained behavior more consistently than diazepam (20 $\mathrm{mg}$ ). In a drug preference study [Griffiths et al., 1980], $400 \mathrm{mg}$ of oral pentobarbital was compared to $200 \mathrm{mg}$ of oral diazepam in sedative abusers. Both drugs were preferred to placebo and, at these doses, produced similar subjective-effect ratings. When compared to each other, the preference was virtually completely in favor of pentobarbital. Thus, the findings that preference and subjective rating do not go hand in hand may in some way be related to the fact that the monkeys report the similarity of their discriminative effects but self-inject barbiturates at higher rates.

\section{Physiological Dependence and Tolerance}

Very little is known about direct physiological dependence development to benzodiazepines in animals [Fraser and Jasinski, 1977]. Nevertheless, a variety of animals have been made physiologicaly dependent to either ethanol or a barbiturate. Benzodiazepines have been studied more extensively as suppressors of withdrawal syndromes. Reliable methods exist for evaluating the suppression of these withdrawal syndromes. It is, however, worth bearing in mind that, unlike the narcotics of the morphine type, there are compounds that suppress barbiturate withdrawal that do not induce dependence upon their chronic administration. These compounds are carisoprodol and tybamate [Fraser and Jasinski, 1977]. It would be appropriate, therefore, to administer a new compound of interest on a chronic basis to insure an appropriate comparison for pharmacological equivalence.

Although it is said often, it bears stating again that proper care must be given to insure that the animal is intoxicated a significant portion of the $24-\mathrm{hr}$ period if not continuously. Likewise, if long-acting compounds are used, the withdrawal syndrome may not occur until long after drug discontinuance. There are a number of good reviews contained in recent volumes [Thompson, 1977; Martin, 1977] dealing with issues relevant to dependence on benzodiazepines.

\section{ACKNOWLEDGMENTS}

The research by G.D. Winger described herein was supported by USPHS Grants from the Nat. Inst. Drug Abuse DA 00254, DA 02230, and by Hoechst/Germany. I thank her for sharing the information with me. The manuscript was typed by M. Gamble and D. Gakle; I wish to thank them for sincere and prompt effort. 


\section{REFERENCES}

Brown, C.R., Sarnquist, F.H., Camp, C.A., and Pedley, T.A.: Clinical, electroencephalographic, and pharmacokinetic studies of a water-soluble benzodiazepine, midazolam maleate. Anesthesiology 50: $467-470,1979$.

Colpaert, F.C., Desmedt, L.K.C., and Janssen, P.A.J.: Discriminative stimulus properties of benzodiazepines, barbiturates, and pharmacologically related drugs; relation to some intrinsic and anticonvulsant effects. Eur. J. Pharmacol. 37: 113-123, 1976.

Deneau, G.A., Yanagita, T., and Seevers, M.H.: Self-administration of psychoactive substances by the monkey. Psychopharmacologia 16: 30-48, 1969.

Fraser, H.F. and Jasinski, D.R.: The assessment of the abuse potentiality of sedative/hypnotics (depressants). Methods used in animals and man. In "Drug Addiction 1," Martin, W.R. (ed.), Berlin: Springer-Verlag, 1977, pp. 589-612.

Griffiths, R.R. and Ator, N.A.: Benzodiazepine self-administration in animals and humans: A comprehensive literature review. In "Benzodiazepines," Ludford, J. and Szara, S. (eds.), National Institute on Drug Abuse Research Monograph Series. Vol. 33. Washington: United States Govt. Printing Office, p 22-36, 1981.

Griffiths, R.R., Bigelow, G.E., and Liebson, I.: Human sedative self-administration: Effects of inter-ingestion interval and dose. J. Pharmacol. Exp. Ther. 197: 488-494, 1976.

Griffiths, R.R., Bigelow, G., and Liebson, I.: Human drug self-administration: Double blind comparison of pentobarbital, diazepam, chlorpromazine, and placebo. J. Pharmacol. Exp. Ther. 210: 301-310, 1979.

Griffiths, R.R., Bigelow, G.E., Liebson, I., and Kaliszak, J.E.: Drug preference in humans: Double blind choice comparison of pentobarbital, diazepam, and placebo. J. Pharmacol. Exp. Ther. 215: 649-661, 1980.

Hackett, D. and Hall, J.M.: Reinforcing properties of intravenous diazepam in rhesus monkeys (Macaca mulatta) with a history of codeine self-administration. In "Clinical Toxicology," Duncan, W.A. and Leonard, B.S. (eds.), Amsterdam: Excerpta Medica, 1977, pp. 308-310.

Herling, S., Valentino, R.J., and Winger, G.: Discriminative stimulus effects of pentobarbital in pigeons. Psychopharmacology (Berlin) 71: 21-28, 1980.

Hoffmeister, F.: Assessment of reinforcing properties of stimulant and depressant drugs in the rhesus monkey as a tool for the prediction of psychic dependence - producing capability in man. In "Predicting Dependence Liability of Stimulant and Depressant Drugs," Thompson, T. and Unna, K. (eds.), Baltimore: University Park Press, 1977, pp. 185-202.

Martin, W.R.: Assessment of depressant abuse liability. In "Predicting Dependence Liability of Stimulant and Depressant Drugs," Thompson, T. and Unna, K. (eds.), Baltimore: University Park Press, 1977, pp. 9-15.

Martin, W.R. (ed.): Drug Addiction. Berlin: Springer-Verlag, 1977

Thompson, T.: Predicting abuse liability of sedatives and stimulants. In "Predicting Dependence Liability of Stimulant and Depressant Drugs," Thompson, T. and Unna, K. (eds.), Baltimore: University Park Press, 1977, pp. 1-8.

Winger, G.D. and Herling, S.: Discriminative stimulus effects of pentobarbital in rhesus monkeys: Tests of stimulus generalization and duration of action. Psychopharmacology (Berlin) (in press).

Yanagita, T. and Takahashi, S.: Development of tolerance to physical dependence on barbiturates in rhesus monkeys. J. Pharmacol. Exp. Ther. 172: 163-169, 1970.

Yanagita, T. and Takahashi, S.: Dependence liability of several sedative-hypnotic agents evaluated in monkeys. J. Pharmacol. Exp. Ther. 185: 307-316, 1973. 